\title{
Clozapine and Haloperidol Reinstate Latent Inhibition Following its Disruption during Amphetamine Withdrawal
}

\author{
Holger Russig, Dipl. Biol., Carol A. Murphy, Ph.D., and Joram Feldon, D. Phil (Oxon.)
}

Latent inhibition (LI) is a behavioral phenomenon whereby repeated exposure to a non-reinforced stimulus retards subsequent conditioning to that stimulus. Deficits in LI may reflect an inability to ignore irrelevant stimuli and are studied as a model of the cognitive/attentional abnormalities found in schizophrenia. We recently determined that pretreatment with escalating doses of the indirect dopamine agonist amphetamine (AMPH; 3 daily injections ip, 1-5 mg/kg, over 6 days) disrupts LI in rats tested in a 2-way active avoidance paradigm during withdrawal. In the present study, we evaluated the effects of the atypical neuroleptic clozapine and the typical neuroleptic haloperidol on the expression of LI on day 4 of AMPH withdrawal. Neuroleptic injections were given either 45 min prior to each of two tone preexposure sessions and a subsequent tone-shock avoidance test session, or only prior to the test session. As expected, saline-injected control groups showed LI during the test session, as reflected by significantly reduced avoidance in tone preexposed vs. nonpreexposed rats. In contrast, animals pretreated with escalating doses of AMPH did not show LI, due to the improved avoidance of the preexposed animals. Both haloperidol $(0.03 \mathrm{mg} / \mathrm{kg})$ and clozapine $(5 \mathrm{mg} / \mathrm{kg})$ largely reversed the disruptive influence of AMPH on LI regardless of whether these drugs were administered prior to both preexposure and test sessions or only prior to the test session. These results provide pharmacological validation for an AMPH withdrawal model of schizophrenic symptoms.

[Neuropsychopharmacology 26:765-777, 2002]

(C) 2002 American College of Neuropsychopharmacology. Published by Elsevier Science Inc.
KEY WORDS: Amphetamine; Clozapine; Haloperidol; Withdrawal; Latent inhibition; Schizophrenia

Amphetamine (AMPH) administration can induce symptoms of psychosis in humans. This outcome is most frequently observed following a chronic high-dose escalating pattern of stimulant abuse (Davis and Schlemmer

From the Laboratory of Behavioral Neurobiology, Swiss Federal Institute of Technology (ETH Zurich), Schorenstrasse 16, CH-8603 Schwerzenbach, Switzerland.

Address correspondence to: Prof. Joram Feldon, Behavioral Neurobiology Laboratory, Swiss Federal Institute of Technology, Postfach Schorenstr. 16, CH-8603 Schwerzenbach, Switzerland, Tel.: +(41)1-655-74-48, Fax: +(41)-1-655-72-03, E-mail: feldon@toxi.biol.ethz.ch

Received July 24, 2001; revised November 6, 2001; accepted November 12, 2001.

Online publication: $12 / 20 / 01$ at www.acnp.org/citations/ Npp122001211.
1980; Angrist 1994). Given that stimulant-induced psychosis resembles the psychosis observed in patients with idiopathic schizophrenia (Ellinwood 1967; Snyder 1973; Brady et al. 1991), it has been suggested that similar neural adaptations could be responsible for the development of these two phenomena. In experimental animals, repeated exposure to AMPH induces behavioral sensitization, a phenomenon that is indicated by a progressive augmentation of behaviors (e.g. locomotion, stereotypies) to subsequent drug challenges and can persist even after prolonged periods of abstinence (Robinson and Becker 1986). Consequently, it has been proposed that studies of the neural bases of behavioral sensitization in animals may yield insights into the neuropathology of schizophrenia (Kokkinidis and Anismann 1980; Robinson and Becker 1986; Liebermann et al. 1990). 
In contrast to the sensitizing effects of repeated psychostimulant challenges on behavior, several reports indicate that withdrawal from repeated stimulant administration induces a state of dysphoria, characterized by symptoms that include anhedonia, anxiety and lethargy. Although such symptoms typically persist for only the first few days of abstinence, these findings have prompted the study of acute psychostimulant withdrawal as an animal model of depression (Leith and Barrett 1976; Kokkinidis et al. 1980, 1986; Geyer and Markou 1995; Barr and Phillips 1999; Lin et al. 1999). Given the proposed links between behavioral sensitization to AMPH in rats and psychosis in humans, and evidence of cross-sensitization between AMPH and stress (Antelman et al. 1980), we recently attempted to further characterize how animals in withdrawal from AMPH might demonstrate altered responses to environmental stimulation. We hypothesized that AMPH-withdrawn animals may also exhibit behaviors consistent with recognized models of schizophrenia.

Many investigators studying animal models of cognitive deficits in schizophrenia have evaluated the behavioral phenomenon of latent inhibition (LI). LI refers to the process whereby repeated exposure to a conditioned stimulus (CS) without consequence impedes the formation of subsequent associations between the CS (e. g. a tone) and a relevant unconditioned stimulus (UCS; e. g. a footshock; Lubow 1973). Reductions in LI have been reported in acute schizophrenic patients (Baruch et al. 1988; Gray et al. 1992, 1995; Vaitl and Lipp 1997; but see Swerdlow et al. 1996; Williams et al. 1998) and these reductions are said to reflect deficits in attentional processing of the previous non-reinforcement of the CS (Lubow 1973; Weiner and Feldon 1997). Moreover, LI in the rat is disrupted by acute AMPH (Solomon et al. 1981; Weiner et al. 1984, 1988; De la Casa et al. 1993; Killcross and Robbins 1993; Weiner and Feldon 1997) and potentiated by neuroleptic drugs (Weiner and Feldon 1987; Christison et al. 1988; Feldon and Weiner 1991; Dunn et al. 1993; Peters and Joseph 1993; Weiner et al. 1997) administered prior to CS preexposure and CS-UCS conditioning. Importantly, AMPH-induced disruptions in LI can also be reversed by neuroleptic treatment (Warburton et al. 1994; Moran et al. 1996; Weiner et al. 1996b). Clinical studies have suggested that neuroleptics have similar enhancement effects on LI in humans (Williams et al. 1996, 1997 but see Williams et al. 1998) in addition to improving performance in other tests of selective attention in which schizophrenics show deficits (Spohn et al. 1977; Braff and Sacuzzo 1982).

We recently observed that pretreatment with escalating doses of AMPH disrupts LI for up to at least two weeks after the last AMPH injection in rats tested in a 2-way active avoidance paradigm (Murphy et al. 2001). We hypothesize that the disruptive effects of AMPH withdrawal on LI may mimic symptoms of cognitive dis- organization similar to those found in schizophrenia. In the first two experiments, we evaluated the effects of administering the typical neuroleptic drug haloperidol, and the atypical neuroleptic drug clozapine, on the disruption of LI induced by AMPH withdrawal when neuroleptic treatments were administered prior to each of two preexposure days and the avoidance conditioning/test session. Because there is evidence that neuroleptics potentiate LI via their action during the conditioning stage (Peters and Joseph 1993; Weiner 1990; Weiner et al. 1997; Shadach et al. 1999, 2000), we also conducted a third experiment in which the effectiveness of these drugs in reversing the LI disruption during AMPH withdrawal was assessed when only a single administration was given, prior to the conditioning/test session. A finding of neuroleptic-induced restoration of LI in AMPH-withdrawn animals would support the study of AMPH withdrawal as a novel animal model for attentional/cognitive processing deficits associated with schizophrenia.

\section{MATERIALS AND METHODS}

\section{Animals}

Male Wistar rats (Zur: WIST (Hanlbm); 250-350 g) obtained from our in-house specific-pathogen-free (SPF) breeding facility were used as subjects in these experiments. During the experiments, animals were housed individually in Macrolon type III cages $(48 \times 27 \times 20 \mathrm{~cm})$ under reversed-cycle lighting (lights on 9 P.M. -9 A.M.) in a temperature $\left(21 \pm 1^{\circ} \mathrm{C}\right)$ and humidity $(55 \pm 5 \%)$ controlled animal facility. Food (Kliba 3430, Klibamühlen, Kaiseraugst $\mathrm{CH}$ ) and water were available ad libitum in the home cages. All experiments were carried out during the dark phase of the light-dark cycle and in agreement with Swiss cantonal regulations for animal experimentation.

\section{Drug Preparation and Administration}

d-Amphetamine sulfate (AMPH; Sigma Chemical Company, St. Louis, U.S.A.) was dissolved in a $0.9 \% \mathrm{NaCl}$ solution to obtain concentrations of $1,2,3,4$ and $5 \mathrm{mg} / \mathrm{ml}$ AMPH (calculated as the salt). Vehicle-treated groups received $0.9 \% \mathrm{NaCl}$ solution (SAL). Haloperidol (HAL; Janssen-Cilag, Baar, Switzerland) was prepared from 5-mg ampoules, in which the drug is present in $1 \mathrm{ml}$ solvent containing $6 \mathrm{mg}$ lactic acid. This solution was subsequently diluted with saline to obtain the required concentration (final pH of 5.5). Clozapine (CLZ; Novartis, Switzerland) was first dissolved in $0.1 \mathrm{~N} \mathrm{HCL}$ in $0.9 \%$ saline solution and then neutralized to $\mathrm{pH} 5.5$ with $\mathrm{Na}_{2} \mathrm{CO}_{3}$. Vehicle-treated animals were administered either HAL vehicle $(0.9 \%$ saline/lactic acid, $\mathrm{pH} 5.5)$ or CLZ vehicle (0.1 N HCL/ $0.9 \%$ saline, $\mathrm{pH}$ 5.5). All solutions were freshly prepared and given intraperitoneally in a volume of $1 \mathrm{ml} / \mathrm{kg}$. 
During the pretreatment period, animals received three injections per day of either AMPH or SAL for six consecutive days, beginning with a $1 \mathrm{mg} / \mathrm{kg}$ dose of AMPH and ending with doses of $5 \mathrm{mg} / \mathrm{kg}$ on the sixth day of the cycle. The control group received injections of saline $(0.9 \%)$ according to the same schedule. The dosing parameters are summarized in Table 1.

\section{Two-Way Avoidance Apparatus}

Behavioral testing was conducted in eight identical shuttle boxes (Coulbourn Instruments, Allentown, PA; model E10-16TC), each set in a sound- and light-attenuating ventilated shell (model E10-20). The internal dimensions of each chamber were $35 \times 17 \times 21.5 \mathrm{~cm}$. The grid floor of the chambers was divided into two identical compartments by an aluminum hurdle $(17 \mathrm{~cm}$ long, $4 \mathrm{~cm}$ high). The barrier was very thin to prevent animals from balancing on it and thus avoiding shock. Footshocks were supplied to the grid floor by a constant direct current source (model E 13-14) and a scanner (model E 13-13) set at $0.5 \mathrm{~mA}$ intensity. During the experimental sessions each chamber was illuminated by a diffuse light source (house light), mounted $19 \mathrm{~cm}$ above the grid floor in the center of the side walls. The conditioned stimulus (CS) was a tone of $85 \mathrm{~dB}$, produced by a tone module (model E 12-02) placed behind the shuttle box on the floor of the shell.

\section{Procedure}

The latent inhibition procedure in the 2-way active avoidance paradigm was conducted over three days: two consecutive daily sessions of preexposure to either the tone and the apparatus or to only the apparatus, and a conditioning session on the third day.

Days 1-2: Exposure to the Tone CS and the Apparatus. The preexposed (PE) rats received 50 presentations of the tone with a duration of $10 \mathrm{~s}$ and a mean variable inter-stimulus interval of $50 \mathrm{~s}$ (range $=10-90 \mathrm{~s}$ ).

Exposure to Only the Apparatus. Each non-preexposed (NPE) animal was placed in the shuttle box with the house light on for a period of $42 \mathrm{~min}$, a duration intended to cor-

Table 1. Escalating-dose Amphetamine Injection Schedule (drug doses in $\mathrm{mg} / \mathrm{kg}$ )

\begin{tabular}{lccc}
\hline \multirow{2}{*}{$\begin{array}{l}\text { Injection } \\
\text { Day }\end{array}$} & \multicolumn{3}{c}{ Injection Times } \\
\cline { 2 - 4 } & 9:00 A.M. & 3:00 P.M. & 9:00 P.M. \\
\hline Day 1 & 1 & 2 & 3 \\
Day 2 & 4 & 5 & 5 \\
Days 3-6 & 5 & 5 & 5 \\
\hline
\end{tabular}

respond with the average length of the PE sessions. No other stimuli were presented. A general evaluation of each animal's activity level (PE and NPE groups) was obtained by recording the total number of crossings during the sessions.

Day 3: Conditioning to the CS. Each animal was placed into the shuttle box and received 100 avoidance trials according to a variable interval schedule of $50 \mathrm{~s}$ (ranging from 10 to $90 \mathrm{~s}$ ). Each avoidance trial began with a 10-s tone followed by a 2-s $0.5 \mathrm{~mA}$ shock, the tone remaining on with the shock. If the rat crossed the barrier to the opposite compartment during the tone, the stimulus was terminated and no shock was delivered (avoidance response). A crossing response during the shock terminated both the tone and the shock (escape response). If the rat failed to cross during the entire tone-shock trial, the tone and the shock terminated after $12 \mathrm{~s}$ (unfinished trial). The total number of intertrial crossings was recorded as an additional measure of locomotor activity.

\section{Experiment 1: Effects of $0.03 \mathrm{mg} / \mathrm{kg}$ Haloperidol Injected prior to Both the Preexposure and Conditioning Sessions on AMPH-induced Abolition of LI during Withdrawal}

In Experiment 1, 62 animals were randomly assigned to one of eight groups in a $2 \times 2 \times 2$ factorial design with main factors of preexposure (PE, NPE), drug pretreatment (SAL, AMPH), and test treatment (SAL, HAL), resulting in four different drug pretreatment/test treatment conditions: saline/saline (SAL/SAL), saline/haloperidol (SAL/HAL), amphetamine/saline (AMPH/SAL) and amphetamine/haloperidol (AMPH/HAL). On each of three days prior to the beginning of the experiment, each rat was handled for an average of $3 \mathrm{~min}$. During the pretreatment phase each subject received either escalating-dose treatment with AMPH or an equivalent schedule of vehicle injections. On days 2 and 3 of withdrawal from AMPH, the two preexposure sessions were administered. The conditioning session took place on day 4 of withdrawal. Each animal received either HAL $(0.03 \mathrm{mg} /$ $\mathrm{kg}$ ) or vehicle $45 \mathrm{~min}$ before the start of preexposure and conditioning sessions on each of the three test days.

Experiment 2: Effects of $5 \mathrm{mg} / \mathrm{kg}$ Clozapine Injected prior to Both the Preexposure and Conditioning Sessions on AMPH-induced Abolition of LI during Withdrawal

Experiment 2 used 58 animals and was conducted according to the design and procedures followed in Experiment 1 . The drug pretreatment/test treatment conditions used in Experiment 2 were as follows: saline/saline (SAL/SAL), saline/clozapine (SAL/CLZ), amphetamine/ 
saline (AMPH/SAL) and amphetamine/clozapine (AMPH/CLZ). Either clozapine $(5 \mathrm{mg} / \mathrm{kg}$ ) or saline was injected $45 \mathrm{~min}$ before the start of preexposure and conditioning sessions on each of the three test days.

Experiment 3: Effects of $5 \mathrm{mg} / \mathrm{kg}$ Clozapine and 0.03 $\mathrm{mg} / \mathrm{kg}$ Haloperidol Injected Only prior to the Conditioning Session on AMPH-induced Abolition of LI during Withdrawal

Experiment 3 used 94 animals and was conducted according to the design and procedures followed in Experiments 1 and 2 except for the fact that animals received one rather than three injections of haloperidol, clozapine or saline during the behavioral testing protocol. The drug pretreatment/test treatment conditions used in experiment 3 were as follows: saline/saline (SAL/SAL), saline/clozapine (SAL/CLZ), saline/haloperidol (SAL/ HAL), amphetamine/saline (AMPH/SAL), amphetamine/clozapine (AMPH/CLZ), and amphetamine/haloperidol (AMPH/HAL). Either clozapine $(5 \mathrm{mg} / \mathrm{kg}$ ), haloperidol $(0.03 \mathrm{mg} / \mathrm{kg})$ or saline was injected $45 \mathrm{~min}$ before the start of the conditioning session on day 4 of withdrawal.

\section{Data Collection and Analysis}

The data were analyzed using StatView version 5.0.1. For the two preexposure sessions in Experiments 1 and 2 , the total number of crossings was assessed using a $2 \times$ $2 \times 2 \times 2$ ANOVA with three between-subjects factors of escalating drug pretreatment (AMPH, SAL), test drug treatment (SAL, HAL or SAL, CLZ), and preexposure (NPE, PE), and with two preexposure days as a withinsubjects factor. For Experiment 3 , we conducted a $2 \times$ $2 \times 2$ ANOVA with the two between-subjects factors of escalating drug pretreatment (AMPH, SAL) and preexposure (NPE, PE), and with two preexposure days as a within-subjects factor.

To facilitate analysis of the conditioning session, the 100 avoidance trials were divided into 10 blocks of 10 trials each. Avoidance responses in Experiments 1 and 2 were analyzed using $2 \times 2 \times 2 \times 10$ ANOVAs consisting of the same three between-subjects main factors as above and a repeated measurements factor of blocks (10 blocks of 10 trials). In Experiment 3, avoidance responses were similarly analyzed using a $2 \times 2 \times 3 \times 10$ ANOVA, the only difference being that the test drug treatment factor consisted of the conditions SAL, HAL, and CLZ. Total numbers of inter-trial crossings were analyzed with $2 \times 2 \times 2$ (Experiment 1 and 2 ) and $2 \times$ $2 \times 3$ (Experiment 3) ANOVAs using the same between-subjects main factors. Whenever a main effect or an interaction between two main factors was significant, a post-hoc t-test was applied examining PE versus NPE differences within drug/test treatment groups or drug/test treatment differences within PE and NPE groups, using the Fisher's protected least significant difference test.

\section{RESULTS}

\section{Experiment 1: Effects of $0.03 \mathrm{mg} / \mathrm{kg}$ Haloperidol Injected prior to Both the Preexposure and Conditioning Sessions on AMPH-induced Abolition of LI during Withdrawal}

Activity during the Preexposure Sessions. Animals made on average significantly fewer crossings on the second day of preexposure (18.4 \pm 1.6 crossings) than on the first day $\left(28.0 \pm 1.1\right.$ crossings), $\left(\mathrm{F}_{1,54}=53.6, p<.0001\right)$, indicating a habituation of spontaneous activity (Table 2). A significant Day $X$ Drug pretreatment $X$ Preexposure interaction, $\left(\mathrm{F}_{1,54}=5.8, p<0.05\right)$, reflected the fact that the AMPH-pretreated PE rats showed decreased crossing activity compared with all the other groups on day 1 , but not on day 2. Haloperidol pretreatment did not influence the total number of crossings made by the animals.

Avoidance Responses during Conditioning. An analysis of numbers of avoidance responses revealed a main effect of Blocks, $\left(\mathrm{F}_{9,486}=54.3, p<.0001\right)$, reflecting an overall increase in avoidance responses as the test session progressed. The presence of LI, that is, faster acquisition of the avoidance response in NPE subjects as compared with PE subjects, was supported by a significant main effect of Preexposure $\left(\mathrm{F}_{1,54}=10.7, p<.002\right)$. However, the expression of LI was significantly different between groups under the four different drug conditions (Drug treatment $X$ Test treatment $X$ Preexposure: $\mathrm{F}_{1,54}=8.6, p<.005$; Blocks $\mathrm{X}$ Drug treatment $\mathrm{X}$ Test treatment $X$ Preexposure: $F_{9,486}=4.7, p<.0001$ ). Figure 1 shows the mean \% avoidance responses for the

Table 2. Means and standard errors of the number of shuttles made during two days of preexposure to the avoidance apparatus and the tone (PE) or only to the apparatus (NPE) in the 4 drug conditions tested in Experiment 1: saline/saline (SAL/SAL), amphetamine/ saline (AMPH/SAL), saline/haloperidol (SAL/HAL), and amphetamine/haloperidol (AMPH/HAL)

\begin{tabular}{llcc}
\hline $\begin{array}{l}\text { Drug } \\
\text { Condition }\end{array}$ & $\begin{array}{c}\text { Preexposure } \\
\text { Condition }\end{array}$ & $\begin{array}{c}\text { PE } \\
\text { Day 1 }\end{array}$ & $\begin{array}{c}\text { PE } \\
\text { Day 2 }\end{array}$ \\
\hline SAL/SAL & NPE & $31 \pm 7$ & $21 \pm 4$ \\
& PE & $33 \pm 5$ & $21 \pm 3$ \\
AMPH/SAL & NPE & $31 \pm 5$ & $17 \pm 3$ \\
& PE & $22 \pm 5$ & $18 \pm 2$ \\
SAL/HAL & NPE & $27 \pm 3$ & $20 \pm 3$ \\
& PE & $32 \pm 3$ & $17 \pm 2$ \\
AMPH/HAL & NPE & $29 \pm 5$ & $19 \pm 4$ \\
& PE & $19 \pm 3$ & $14 \pm 3$ \\
\hline
\end{tabular}


A
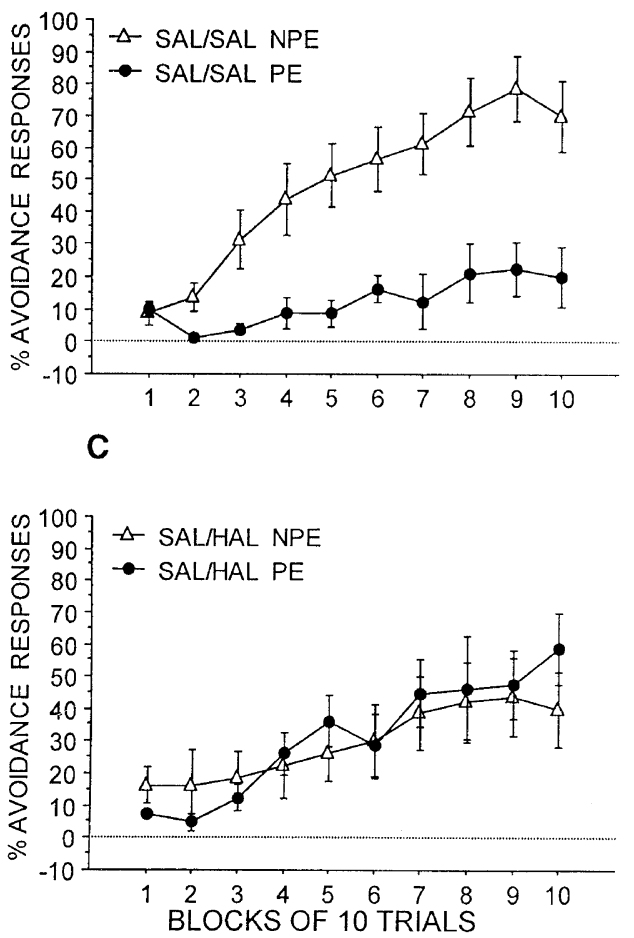

B
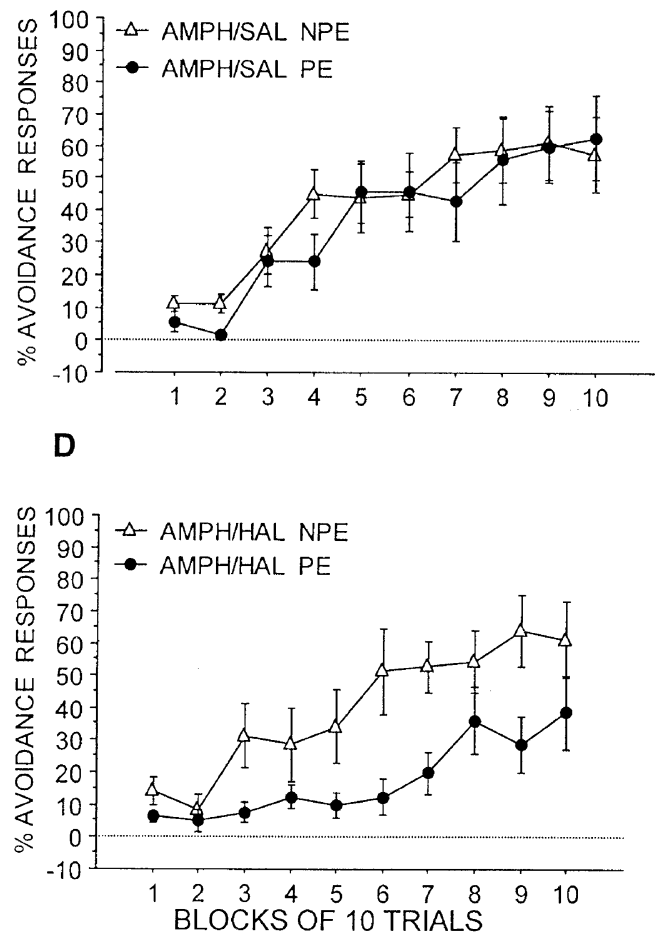

Figure 1. Percent avoidance responses made during a 100-trial test of conditioned 2-way active avoidance acquisition in animals belonging to one of four different drug pretreatment/test treatment conditions in Experiment 1. A: saline/saline (SAL/ $\mathrm{SAL}, \mathrm{n}=16)$; $\mathrm{B}$ : amphetamine/saline (AMPH/SAL, $\mathrm{n}=15)$; $\mathrm{C}$ : saline/haloperidol (SAL/HAL, $\mathrm{n}=16$ ); $\mathrm{D}$ : amphetamine/haloperidol (AMPH/HAL, $n=15)$. Animals were preexposed either to the apparatus (NPE) or to the tone and the apparatus (PE). Data are expressed as averages of 10 blocks of 10 consecutive trials each. Values are means \pm S.E.M.

PE and NPE groups in the four drug conditions. As can be seen in Figure 1, LI is disrupted in the AMPH/SAL and SAL/HAL conditions but not in the SAL/SAL and AMPH/HAL conditions. This was supported by post hoc analyses showing that LI was present in the SAL/ SAL control group (NPE vs. PE, $p<.0005$ ) and the AMPH/HAL condition (NPE vs. PE, $p<.02$ ), but absent in the AMPH/SAL condition (NPE vs. PE, $p=$ .6279 ) and SAL/HAL condition (NPE vs. PE, $p=.8673$ ). It can be seen in Figure 1 that the abolition of LI in the AMPH/SAL condition was primarily due to increased avoidance responses in the PE group (SAL/SAL PE vs. AMPH/SAL PE, $p=.0173$; SAL/SAL NPE vs. AMPH/ SAL NPE, $p=.4660)$, whereas the absence of LI in the SAL/HAL condition was due to both increased avoidance responses in the PE group and decreased avoidance responses in the NPE group (SAL/SAL PE vs. SAL/ HAL PE, $p=.036$; SAL/SAL NPE vs. SAL/HAL NPE, $p=.0988)$.

An analysis performed on the total number of intertrial crossings made by animals during the test session revealed on average a higher number of shuttles in PE animals $(25.6 \pm 3.3$ crossings $)$ relative to NPE animals
(17.0 \pm 1.9 crossings), $\left(\mathrm{F}_{1,54}=4.7, p<.04\right)$. No effects of Drug pretreatment or Test treatment were detected (data not shown).

\section{Experiment 2: Effects of $5 \mathrm{mg} / \mathrm{kg}$ Clozapine Injected prior to Both the Preexposure and Conditioning Sessions on AMPH-induced Abolition of LI during Withdrawal}

Activity during the Preexposure Sessions. A comparison of the total number of crossings during the two preexposure sessions revealed a significant effect of Days $\left(\mathrm{F}_{1,50}=54.7, p<.0001\right)$, reflecting a generally higher number of crossings on the first preexposure day compared with the second day (values averaged over groups: $25 \pm 3$ for session 1 vs. $15 \pm 2$ for session 2 , see Table 3). Clozapine reduced the total number of crossings (SAL $=31 \pm 2$ vs. CLZ $=9 \pm 1$ ), as supported by a main effect of Test treatment $\left(\mathrm{F}_{1,50}=45.8, p<.0001\right)$, but there were no significant main effects or interactions involving the factors of Preexposure or Drug pretreatment. 
Table 3. Means and standard errors of the number of shuttles made during two days of preexposure to the avoidance apparatus and the tone (PE) or only to the apparatus (NPE) in the 4 drug conditions tested in Experiment 2: saline/saline (SAL/SAL), amphetamine/ saline (AMPH/SAL), saline/clozapine (SAL/CLZ), and amphetamine/clozapine (AMPH/CLZ)

\begin{tabular}{llrr}
\hline $\begin{array}{l}\text { Drug } \\
\text { Condition }\end{array}$ & $\begin{array}{c}\text { Preexposure } \\
\text { Condition }\end{array}$ & $\begin{array}{c}\text { PE } \\
\text { Day 1 }\end{array}$ & $\begin{array}{c}\text { PE } \\
\text { Day 2 }\end{array}$ \\
\hline SAL/SAL & NPE & $46 \pm 9$ & $23 \pm 6$ \\
& PE & $44 \pm 6$ & $26 \pm 6$ \\
AMPH/SAL & NPE & $29 \pm 5$ & $23 \pm 6$ \\
& PE & $36 \pm 8$ & $21 \pm 7$ \\
SAL/CLZ & NPE & $6 \pm 2$ & $7 \pm 2$ \\
& PE & $10 \pm 3$ & $9 \pm 2$ \\
AMPH/CLZ & NPE & $17 \pm 3$ & $7 \pm 1$ \\
& PE & $10 \pm 2$ & $6 \pm 1$ \\
\hline
\end{tabular}

Avoidance Responses during Conditioning. The $2 \times 2 \times$ $2 \times 10$ ANOVA revealed a highly significant main effect of Blocks $\left(\mathrm{F}_{9,450}=61.9, p<.0001\right)$, indicating an overall increase in avoidance responses as the avoidance test session progressed. However, clozapine slightly decreased numbers of avoidance responses, as supported by a main effect of Test treatment $\left(\mathrm{F}_{1,50}=5.4, p<.03\right)$. In addition, the analysis revealed a significant main effect of Preexposure $\left(\mathrm{F}_{1,50}=16.2, p<.0003\right)$, as well as a significant interaction of Preexposure X Blocks $\left(\mathrm{F}_{9,450}=3.6\right.$, $p<.0003$ ), supporting the conclusion that overall, the NPE subjects acquired the avoidance response faster and to a greater degree than the PE subjects, that is, LI was present. Figure 2 illustrates the mean \% avoidance responses of the PE and the NPE groups in each of the four drug conditions. A clear LI effect was seen in the SAL/SAL condition. In contrast, LI was completely absent in the AMPH/SAL condition due to the increased avoidance responses in the PE group (SAL/SAL PE vs. AMPH/SAL PE, $p=.0105$; SAL/SAL NPE vs. AMPH/ SAL NPE, $p=.6565)$, but was restored when AMPH pretreatment was coupled with CLZ test treatment. In the SAL/CLZ condition, although LI was not significant when analyzed over the entire test session, a clear LI effect can be seen after the first 50 trials. These outcomes were supported by Fisher's post hoc tests revealing significant LI in the SAL/SAL (PE vs. NPE, $p=$ $.0006)$ and AMPH/CLZ (PE vs. NPE, $p=.0324)$ conditions, but not in the AMPH/SAL (PE vs. NPE, $p=.7207$ ) and SAL/CLZ (PE vs. NPE, $p=.1329$ ) conditions. The overall ANOVA showed a near-significant Drug treatment $X$ Test treatment $X$ Preexposure interaction $\left(\mathrm{F}_{1,50}=\right.$ 3.1, $p=.0843)$ due to this combination of effects. Finally, the analysis performed on the total number of inter-trial crossings made by animals during the test session revealed on average a higher number of crosses in
PE animals (35.4 \pm 3.7 crossings) relative to NPE animals $(25.1 \pm 2.8$ crossings $),\left(\mathrm{F}_{1,50}=5.0, p<.03\right)$. We attribute the finding of more inter-trial interval shuttles in PE than NPE animals in Experiments 1 and 2 to the decreased learning of the PE groups leading to an increased generalization of the shuttling response. Numbers of inter-trial interval crosses were not significantly affected by either Drug treatment or Test treatment (data not shown).

\section{Experiment 3: Effects of $0.03 \mathrm{mg} / \mathrm{kg}$ Haloperidol and $5 \mathrm{mg} / \mathrm{kg}$ Clozapine Injected Only prior to the Conditioning Session on AMPH-induced Abolition of LI during Withdrawal}

Activity during the Preexposure Sessions. The total number of crossings decreased over the two preexposure sessions, indicating habituation to the apparatus (significant effect of Days: $\mathrm{F}_{1,90}=37.6, p<.0001$ ). There was also a significant main effect of Drug $\left(\mathrm{F}_{1,90}=8.1, p<.0055\right)$ reflecting the fact that AMPH pretreated animals crossed less often than the SAL animals, mainly on the first preexposure day (Table 4). This result is consistent with what we have suggested previously (Murphy et al. 2001), that animals withdrawn from escalating AMPH administration at times show a mild depression of motor activity. There was no significant main effect or interaction including the factor of Preexposure.

Avoidance Responses during Conditioning. As in the first two experiments, the analysis revealed a highly significant effect of Blocks $\left(\mathrm{F}_{9,738}=50.2, p<.0001\right)$, reflecting increased avoidance responses over the 10 blocks of 10 trials. The generally higher number of avoidance responses in NPE compared with PE animals, that is, LI, was supported by a significant main effect of Preexposure $\left(\mathrm{F}_{1,82}=24.3, p<.0001\right)$ and a significant interaction of Preexposure X Blocks $\left(\mathrm{F}_{9,738}=4.0\right.$, $p<.0001$ ). A single injection of $0.03 \mathrm{mg} / \mathrm{kg}$ haloperidol decreased numbers of avoidance responses independently of preexposure condition, as reflected by a significant main effect of Test treatment $\left(\mathrm{F}_{2,82}=8.6, p<\right.$ $.0005)$ and a significant interaction of Test treatment $X$ Blocks $\left(\mathrm{F}_{18,738}=3.6, p<.0001\right)$. In contrast, clozapine-injected animals did not exhibit a generalized depression of avoidance responses. As seen in Figure 3, the expression of LI was again significantly influenced by both AMPH and neuroleptic treatments, as supported by the significant interactions of Drug treatment $X$ Preexposure $\left(\mathrm{F}_{1,82}=4.8, p<.04\right)$, Drug treatment $\mathrm{X}$ Preexposure $X$ Test treatment $\left(\mathrm{F}_{2,82}=3.7, p<.03\right)$ and of Drug treatment $X$ Preexposure $X$ Test treatment $X$ Blocks $\left(\mathrm{F}_{18,738}=\right.$ $1.7, p<.04)$. A clear LI effect was seen in all three SAL conditions (SAL/SAL, SAL/CLZ, and SAL/HAL). In contrast LI was completely abolished in the AMPH/ SAL condition due to an increase of avoidance re- 
A

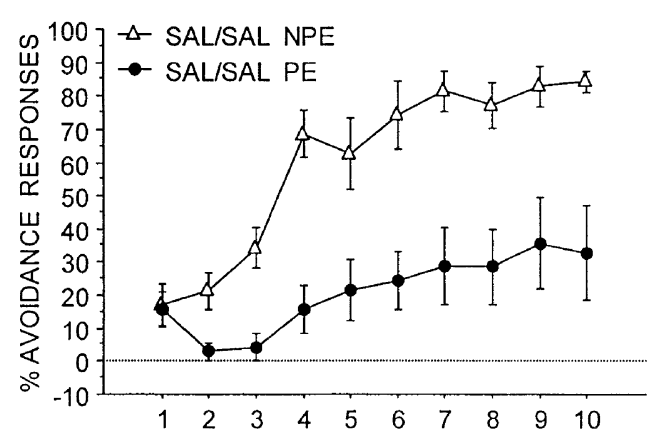

C

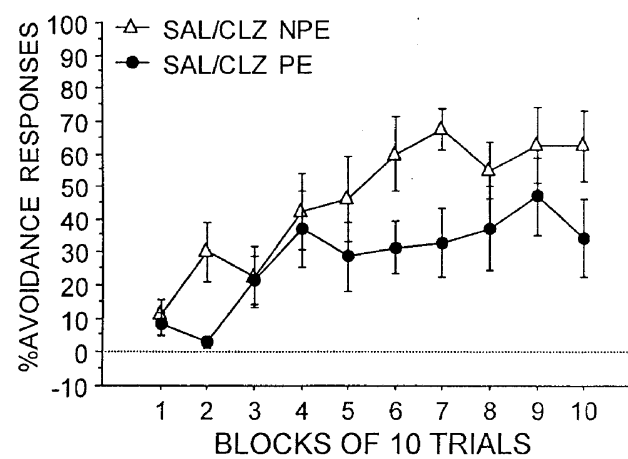

B

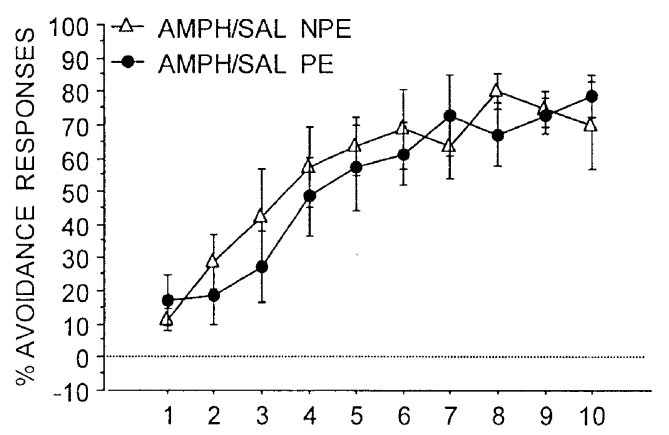

D

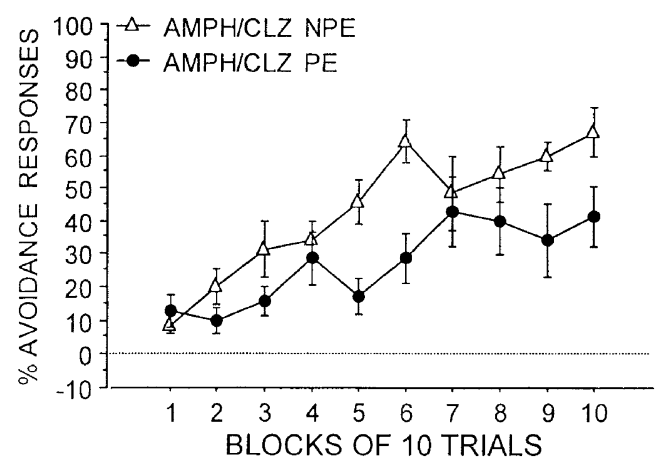

Figure 2. Percent avoidance responses made during a 100-trial test of conditioned 2-way active avoidance acquisition in animals belonging to one of four different drug pretreatment/test treatment conditions in Experiment 2. A: saline/saline (SAL/SAL, $\mathrm{n}=14$ ); B: amphetamine/saline (AMPH/SAL, $\mathrm{n}=15$ ); C: saline/clozapine (SAL/CLZ, $\mathrm{n}=15$ ); D: amphetamine/clozapine (AMPH/CLZ, $n=14)$. Animals were preexposed either to the apparatus (NPE) or to the tone and the apparatus (PE). Data are expressed as averages of 10 blocks of 10 consecutive trials each. Values are means \pm S.E.M.

sponses in the PE group (SAL/SAL PE vs. AMPH/SAL $\mathrm{PE}, p=.0007$; SAL/SAL NPE vs. AMPH/SAL NPE, $p=$ .1711). Moreover, in the AMPH/CLZ and AMPH/HAL conditions, LI was restored by a single injection of clozapine or haloperidol administered prior to testing. These outcomes were supported by Fisher's post hoc tests that revealed significant LI in the SAL/SAL (NPE vs. PE, $p=.0046)$, SAL/CLZ (NPE vs. PE, $p=.0268$ ), SAL/HAL (NPE vs. PE, $p=.0035$ ) and AMPH/HAL (NPE vs. PE, $p=.0413$ ) conditions and a near-significant effect in the AMPH/CLZ (NPE vs. PE, $p=.0567$ ) condition. In contrast, in the AMPH/SAL condition, PE

Table 4. Means and standard errors of the number of shuttles made during two days of preexposure to the avoidance apparatus and the tone (PE) or only to the apparatus (NPE) in the 2 drug conditions tested in Experiment 2: saline (SAL) and amphetamine (AMPH)

\begin{tabular}{llcc}
\hline $\begin{array}{l}\text { Drug } \\
\text { Condition }\end{array}$ & $\begin{array}{c}\text { Preexposure } \\
\text { Condition }\end{array}$ & $\begin{array}{c}\text { PE } \\
\text { Day 1 }\end{array}$ & $\begin{array}{c}\text { PE } \\
\text { Day 2 }\end{array}$ \\
\hline SAL & NPE & $44 \pm 4$ & $32 \pm 4$ \\
& PE & $39 \pm 4$ & $30 \pm 4$ \\
AMPH & NPE & $26 \pm 2$ & $20 \pm 2$ \\
& PE & $33 \pm 4$ & $28 \pm 4$ \\
\hline
\end{tabular}

animals performed even slightly better than NPE animals toward the end of the session (NPE vs. PE, $p=$ .1611). Finally, the analysis of inter-trial crossings during the test session revealed a significant main effect of Test treatment $\left(\mathrm{F}_{2,82}=4.874, p<.02\right)$ as well as a significant interaction of Test treatment $\mathrm{X}$ Blocks $\left(\mathrm{F}_{18,738}=\right.$ 2.714, $p<.0003$ ). Post-hoc tests showed that CLZ treated animals crossed more often during the intertrial intervals $(43.5 \pm 5.6$ crossings) compared with HAL treated rats ( $23.7 \pm 3.3$ crossings), but neither of the neuroleptic treated groups were significantly different from the SAL animals ( $30.9 \pm 4.5$ crossings), which showed an intermediate number of crossings (HAL vs. CLZ, $p=.0034$; SAL vs. HAL, $p=.2734$, SAL vs. CLZ, $p$ $=.0556)$. There were no significant main effects or interactions including the factors of Drug treatment or Preexposure (data not shown).

\section{DISCUSSION}

The present study demonstrated that withdrawal from an escalating dose schedule of AMPH disrupts LI, replicating the findings of our previous study (Murphy et al. 2001). LI was clearly present in all SAL/SAL control 
A

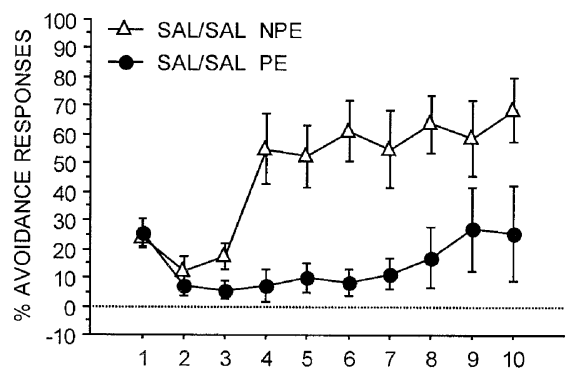

C

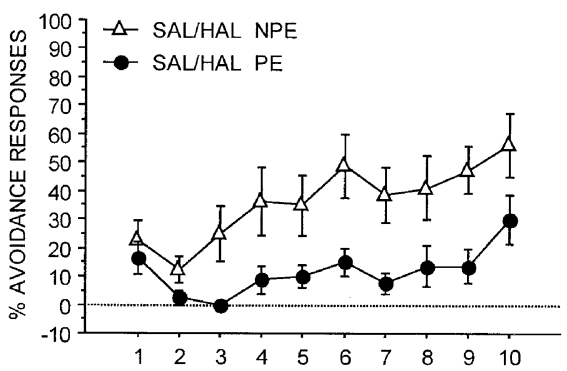

E

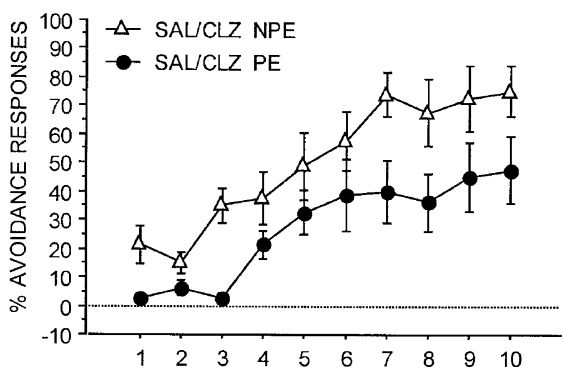

BLOCKS OF 10 TRIALS
B
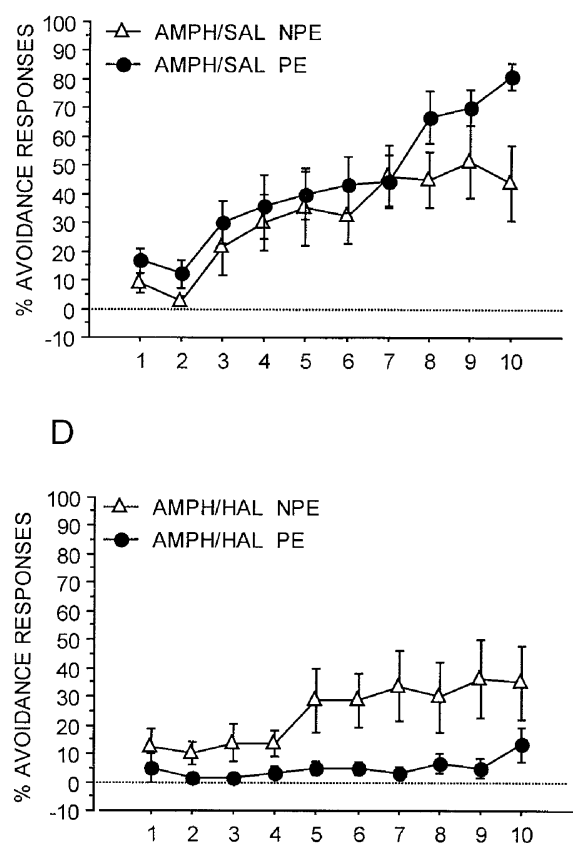

\section{$\mathrm{F}$}

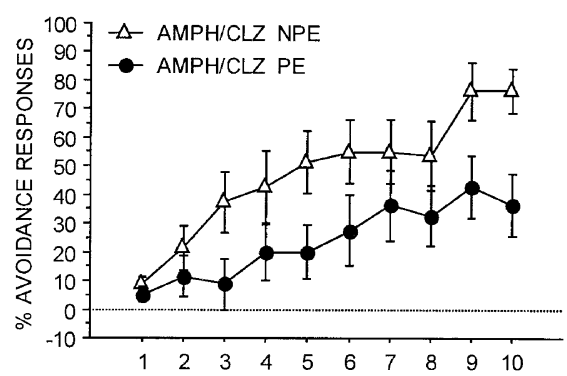

BLOCKS OF 10 TRIALS
Figure 3. Percent avoidance responses made during a 100-trial test of conditioned 2-way active avoidance acquisition in animals belonging to one of 6 different drug pretreatment/test treatment conditions in Experiment 3. A: saline/saline (SAL/SAL, $\mathrm{n}=15$ ); $\mathrm{B}$ : amphetamine/saline (AMPH/SAL, $\mathrm{n}=15$ ); C: saline/haloperidol (SAL/ HAL, $\mathrm{n}=16)$; D: amphetamine/haloperidol (AMPH/HAL, $\mathrm{n}=16)$; $\mathrm{E}$ : saline /clozapine (SAL/CLZ, $\mathrm{n}=16$ ); F: amphetamine/clozapine (AMPH/ CLZ, $\mathrm{n}=16$ ). Animals were preexposed either to the apparatus (NPE) or to the tone and the apparatus (PE). Data are expressed as averages of 10 blocks of 10 consecutive trials each. Values are means \pm S.E.M. groups in that the SAL/SAL PE groups showed a significantly decreased number of avoidance responses in comparison to the NPE groups. In contrast, LI was abolished during AMPH withdrawal, due to an increased number of avoidance responses of the AMPH/ SAL PE group. Moreover, treatment with the typical neuroleptic drug HAL during withdrawal, whether administered prior to both the preexposure and test sessions or only prior to the test session, reversed the disruptive effects of AMPH withdrawal on LI. Treatment with the atypical neuroleptic agent CLZ was only slightly less effective in reversing disrupted LI during AMPH withdrawal, resulting in significant and nearsignificant ( $p=.057$ ) LI in Experiments 2 and 3, respectively. These results represent the first demonstration that AMPH-withdrawal induced deficits in LI, like AMPH-induced disruptions in LI, can be reversed by neuroleptic treatment.
The low doses of HAL $(0.03 \mathrm{mg} / \mathrm{kg})$ and CLZ $(5 \mathrm{mg} /$ $\mathrm{kg}$ ) used in this study were selected because they were expected to restore LI in AMPH-withdrawn animals without influencing avoidance performance or activity level per se. This was a matter for concern given that both typical and atypical antipsychotic drugs are known to disrupt conditioned active avoidance in rats independently of any effects on LI (Niemegeers et al. 1969; Arnt 1982; Ogren and Archer 1994). In order to index activity levels in the various drug conditions, numbers of spontaneous shuttles during the preexposure sessions and numbers of inter-trial interval shuttles during avoidance testing were recorded. In Experiment 1, HAL did not influence the total number of shuttles recorded during the preexposure sessions; in contrast, in Experiment 2, CLZ reduced the number of crossings during the preexposure sessions, but in PE and NPE groups equally. This result suggests that the $5-\mathrm{mg} / \mathrm{kg}$ 
CLZ treatment exerted a mild sedative effect in the animals in the second experiment. However, neither HAL nor CLZ test treatment influenced numbers of inter-trial interval shuttles during the test session in Experiments 1 and 2 and CLZ treated animals showed near-significantly more inter-trial shuttles compared with SAL treated animals in Experiment 3. These results suggest that neuroleptic-induced restoration of LI is unrelated to drug effects on locomotor activity/shuttling behavior. Nevertheless, a slight depression of avoidance responses was observed following treatment with both HAL (Experiments 1 and 3) and CLZ (Experiment 2).

We did not see neuroleptic-induced enhancement of $\mathrm{LI}$ in our SAL/HAL or SAL/CLZ conditions. The absence of a HAL- or CLZ-induced enhancement of LI was most likely due to the fact that we used a procedure with a relatively high number of CS preexposures where the control animals showed normal LI. It is reportedly difficult to demonstrate neuroleptic-induced increases on a background of normal LI in control animals (Weiner and Feldon 1997; Moser et al. 2000). However, the converse reduction of LI in the neuroleptic-treated groups, particularly in Experiments 1 and 2, merits some discussion. In the case of CLZ, the LI reduction was mostly due to decreased avoidance responses in the NPE groups (in both the SAL/CLZ and AMPH/CLZ NPE conditions). Thus, the reduced LI of these groups was probably due to the mild sedative and anti-avoidance effects of CLZ in this paradigm, as suggested previously. In the SAL/HAL groups, however, both decreased avoidance in the NPE animals and increased avoidance in the PE animals were responsible for their reduced LI; moreover, this effect was not observed in the AMPH/ HAL animals, which did show LI. Interestingly, it has been shown that both stress and HAL-induced supersensitivity can exacerbate disruptions in LI (Solomon et al. 1981; Hellman et al. 1983). We can speculate that perhaps the stress of receiving 18 SAL injections combined with repeated low-dose HAL treatment during withdrawal contributed to the observed deficit in LI. The converse reinstatement of LI in the AMPH/HAL group suggests that the brain's response to haloperidol is very different in AMPH-withdrawn and SAL animals.

It is also worth noting that disruptions in LI following neuroleptic treatment have been observed previously, particularly with high doses of HAL and CLZ (Dunn et al. 1993; Warburton et al. 1994; Moran et al. 1996; Williams et al. 1998). Consequently, the neuroleptic-induced reductions in LI in the control groups may be due at least in part to a cumulative effect of administering three injections, particularly since following a single injection (Experiment 3), LI was expressed in the SAL/HAL condition. LI was likewise more robust in the SAL/CLZ condition following only a single administration in Experiment 3 than following the three injections of Experiment 2. Interestingly, it has been demon- strated that the half-life time of HAL in brain tissue is longer than that of many other neuroleptics, such that both active avoidance and apomorphine-induced activity can be reduced by haloperidol administered on previous days (Weiner et al. 1987; Cohen et al. 1992). Such phenomena could underlie the more pronounced ability of repeated HAL compared with repeated CLZ administration to reduce LI.

Several investigators have reported that the phase at which neuroleptics potentiate LI is the conditioning rather than preexposure stage (Peters and Joseph 1993; Weiner 1990; Weiner and Feldon 1997; Weiner et al. 1997; Shadach et al. 1999, 2000). The results of Experiment 3 indicate that it is likewise sufficient to treat animals with neuroleptics only before the conditioning stage in order to normalize AMPH withdrawal-induced LI disruption in the active avoidance paradigm. This being said, it is of course possible that neuroleptic administration prior only to the preexposure session could mediate changes in LI as well (Shadach et al. 2000), a possibility not examined in the present investigation. Nevertheless, our findings suggest that AMPH withdrawal disrupts LI via an effect on either acquisition of the CS-US association or expression of the learned response rather than strictly by modulating the degree of attention to the non-reinforced CS during preexposure.

In order to understand the pharmacological basis of these neuroleptic effects, it will be important to identify the neurochemical substrates underlying AMPH withdrawal-induced LI deficits. There is considerable evidence that the mesolimbic dopamine (DA) system, especially the nucleus accumbens, plays a key role in the expression of LI (Solomon and Staton 1982; Young et al. 1993; Gray et al. 1997; Murphy et al. 2000). Specifically, an attenuation of LI has been linked to increased DA activity in the nucleus accumbens (Solomon and Staton 1982; Gray et al. 1997). In contrast, previous reports have indicated that AMPH withdrawal is associated with either a reduction or no change in basal DA levels (Rossetti et al. 1992; Segal and Kuczenski 1992; Crippens et al. 1993; Paulson and Robinson 1995; Weiss et al. 1997). Similarly, studies from our lab using in vivo microdialysis have indicated unchanged basal levels of DA in both the core and shell subregions of the nucleus accumbens on day 4 of withdrawal from the escalating dose schedule of $\mathrm{AMPH}$ used in this study (Pezze et al. In press).

It appears paradoxical that on the one hand studies have shown the necessity of higher accumbens DA activity to disrupt LI, yet on the other hand basal levels of accumbens DA are unchanged or reduced after AMPH withdrawal. However, stressful stimuli normally evoke DA release in the nucleus accumbens (Roth et al. 1988; Abercrombie et al. 1989) such that an altered sensitivity of the mesolimbic system to stress during AMPH withdrawal could contribute to the effects on LI. Microdialysis experiments with this escalating dose sched- 
ule of AMPH have revealed decreased DA release in the shell and increased DA activity in the core subregion relative to SAL-treated animals during the expression of a conditioned fear response on day 4 of withdrawal (Pezze et al. In press). There is evidence that DA release in the shell rather than the core subregion of the accumbens may be particularly important to the expression of LI (Murphy et al. 2000). In addition, lesions of the shell subterritory of the nucleus accumbens lead to a disappearance of LI, whereas lesions to the core subterritory leave LI intact (Weiner et al. 1996a). We can speculate that dysregulation of core and shell DA transmission, particularly decreased DA release in the shell of AMPHwithdrawn animals during avoidance learning, may contribute to their disruption of LI. Furthermore, haloperidol and clozapine may act to reinstate LI by reducing the resulting imbalance in postsynaptic transmission, via direct receptor antagonism or by indirectly modulating DA release in these regions (Broderick and Piercey 1998; Kuroki et al. 1999).

Both HAL and CLZ bind to $\mathrm{D}_{2}$ receptors, although the two drugs show differential affinities within the $\mathrm{D}_{1}$ like and $\mathrm{D}_{2}$-like receptor subfamilies (Van Tol et al. 1991; Schotte et al. 1996). Clozapine also binds with high affinity to serotonergic, $\alpha$-adrenergic and muscarinic receptors (Meltzer 1989; Schotte et al. 1996). However, since haloperidol binds with greatest affinity to the $\mathrm{D}_{2}$ subtype, the very low dose of HAL used in this study most likely acted on $\mathrm{D}_{2}$ receptors. It is conceivable that upregulation of $\mathrm{D}_{2}$ receptor populations or transduction mechanisms, particularly in the nucleus accumbens, could contribute to the disruption of LI in the AMPH/SAL conditions such that neuroleptic-induced $\mathrm{D}_{2}$ blockade would lead to a consequent normalization of behavior. In support of this hypothesis, Levy et al. (1988) showed that following intermittent pretreatment with $\mathrm{AMPH}$, animals showed heightened responsiveness to a $D_{2}$ but not a $\mathrm{D}_{1}$ agonist, an effect that persisted for at least 30 days after the last injection. However, receptor binding studies on the effects of withdrawal from chronic AMPH have provided mixed results. Chen et al. (1999) demonstrated reduced numbers of $\mathrm{D}_{2}$ receptors in the ventral striatum and diminished D2-mediated behavioral responses during withdrawal from intermittent AMPH administration. Other investigators have shown no effect of chronic AMPH treatment on $\mathrm{D}_{2}$ receptor binding (Kalivas and Stewart 1991; Bonhomme et al. 1995; Zhang et al. 2000a). Autoreceptor subsensitivity has been observed in the ventral tegmental area during AMPH withdrawal (Wolf et al. 1993) but the transient nature of this effect makes it an unlikely mechanism for the effects on LI, which persist for at least the first 2 weeks of withdrawal (Murphy et al. 2001).

It may be that post- $\mathrm{D}_{2}$ receptor mechanisms or effects on other neurotransmitter systems contribute to the behavioral changes observed during AMPH with- drawal. For example, altered $\mathrm{GABA}_{\mathrm{B}}$ receptor coupling to G-proteins was recently reported during withdrawal from AMPH (Zhang et al. 2000b). Furthermore, although our results suggest that neuroleptic-induced recovery of LI is most likely due to $D_{2}$ receptor blockade, we cannot rule out the possibility that clozapine and haloperidol may have reinstated LI via separate mechanisms of action, or that other receptor or neurotransmitter systems were also involved in mediating these neuroleptic effects. In particular, serotonergic systems have been implicated in the mediation of LI (Moser et al. 1996; Hitchcock et al. 1997) and both clozapine, and with less affinity, haloperidol, target serotonin as well as DA receptors (Meltzer 1989; Schotte et al. 1996). Even if we assume that the neuroleptic-induced reinstatement of $\mathrm{LI}$ is $\mathrm{D}_{2}$-receptor mediated, the fact that recovered LI in the drug-treated groups was not as great as that in the SAL/SAL animals makes it difficult to say whether the AMPH withdrawalinduced deficit in LI can be entirely or only partially reinstated by this mechanism.

Recent PET imaging studies have implicated sensitization-like phenomena in the expression of positive psychotic symptoms (Laruelle 2000), the class of symptoms against which neuroleptic treatments are most effective. The present study demonstrated that AMPH withdrawal-induced disruptions in LI can be restored by both a typical and an atypical neuroleptic drug. Although much more work still needs to be done, these findings provide validating evidence that the state of AMPH withdrawal can be considered a potentially relevant animal model for the positive symptoms of schizophrenia. An advantage of an AMPH withdrawal model is that behavioral assessments can be made during the drug-free withdrawal period, thus avoiding the potential drug-drug interactions that characterize many other pharmacologically-induced animal models of schizophrenia. The neuroadaptations induced by repeated AMPH treatment are more likely to model the chronic changes found in a schizophrenic brain than would any acute treatment, as supported by evidence of apparently permanent behavioral sensitization phenomena following AMPH treatments of this kind (Paulson et al. 1991; Russig et al. 2001). Moreover, the relatively persistent nature of the deficit in LI during AMPH withdrawal (Murphy et al. 2001) allows for flexibility in the duration of test drug administration. It is hoped that this experimental paradigm may eventually prove useful for the detection of neuroleptic characteristics of potential psychotherapeutics.

\section{ACKNOWLEDGMENTS}

This study was supported by the Swiss Federal Institute of Technology (ETH-Zurich, Switzerland). We would like to thank the staff of the animal facility for their care and maintenance of the animals used in this study, Mr. Peter Schmid for 
his valuable technical assistance, and Mrs. Bonnie Strehler for her secretarial help.

\section{REFERENCES}

Abercrombie ED, Keefe KA, DiFrischia DS, Zigmond MJ (1989): Differential effect of stress on in vivo dopamine release in striatum, nucleus accumbens, and medial prefrontal cortex. J Neurochem 52:1655-1658

Angrist B (1994): Amphetamine psychosis: clinical variations of the syndrome. In Cho AK, Segal DS (eds), Amphetamine and its analogs, San Diego, Academic Press, pp 387-414

Antelman SM, Eichler AJ, Black CA, Kocan D (1980): Interchangeability of stress and amphetamine in sensitization. Science 207:329-331

Arnt J (1982): Pharmacological specificity of conditioned avoidance response inhibition in rats: inhibition by neuroleptics and correlation to dopamine receptor blockade. Acta Pharmacol Toxicol 51:321-329

Barr AM, Phillips AG (1999): Withdrawal following repeated exposure to $\mathrm{d}$-amphetamine decreases responding for a sucrose solution as measured by progressive ratio schedule of reinforcement. Psychopharmacology (Berl) 141:99-106

Baruch I, Hemsley DR, Gray JA (1988): Differential performance of acute and chronic schizophrenics in a latent inhibition task. J Nerv Ment Dis 176:598-606

Bonhomme N, Cador M, Stinus L, Le Moal M, Spampinato U (1995): Short and long-term changes in dopamine and serotonin receptor binding sites in amphetamine-sensitized rats: a quantitative autoradiographic study. Brain Res 675:215-223

Brady KT, Lydiard RB, Malcom R, Ballenger JC (1991): Cocaine-induced psychosis. J Clin Psychiatry 52:509-512

Braff DL, Sacuzzo DP (1982): Effect of antipsychotic medication on speed of information processing in schizophrenic patients. Am J Psychiatry 139:1127-1130

Broderick PA, Piercey MF (1998): Clozapine, haloperidol, and the $\mathrm{D}_{4}$ antagonist PNU-101387G: in vivo effects on mesocortical, mesolimbic, and nigrostriatal dopamine and serotonin release. J Neural Transm 105:749-767

Chen J-C, Su H-J, Huang L-I, Hsie M-C (1999): Reductions in binding and functions of $\mathrm{D}_{2}$ dopamine receptors in the rat ventral striatum during amphetamine sensitization. Life Sci 64:343-354

Christison GW, Atwater GE, Dunn LA, Kilts CD (1988): Haloperidol enhancement of latent inhibition: Relation to therapeutic action? Biol Psychiatry 23:746-749

Cohen BM, Tsuneizumi T, Baldessarini RJ, Campbell A, Babb SM (1992): Differences between antipsychotic drugs in persistence of brain levels and behavioral effects. Psychopharmacology (Berl) 108:338-344

Crippens D, Camp DM, Robinson TE (1993): Basal extracellular dopamine in the nucleus accumbens during amphetamine withdrawal: a "no net flux" microdialysis study. Neurosci Lett 164:145-148

Davis JM, Schlemmer FP Jr (1980): The amphetamine psychosis. In Caldwell J (ed), Amphetamines and Related
Stimulants: Chemical, Biological, Clinical and Social Aspects. Boca Raton, CRC Press, pp 161-173

De la Casa LG, Ruiz G, Lubow RE (1993): Amphetamineproduced attenuation of latent inhibition is modulated by stimulus preexposure duration: Implications for schizophrenia. Biol Psychiatry 33:707-711

Dunn LA, Atwater GE, Kilts CD (1993): Effects of antipsychotic drugs on latent inhibition-sensitivity and specificity of an animal behavioral model of clinical drug action. Psychopharmacology (Berl) 112:315-323

Ellinwood EH (1967): Amphetamine psychosis: I. Description of the individuals and process. J Nerv Ment Dis 144:273-283

Feldon J, Weiner I (1991): The latent inhibition model of schizophrenic attention disorder: Haloperidol and sulpiride enhance rats' ability to ignore irrelevant stimuli. Biol Psychiatry 29:635-646

Geyer MA, Markou A (1995): Animal models of psychiatric disorders. In Bloom FE, Kupfer DJ (eds), Psychopharmacology: the Fourth Generation of Progress. New York, Raven Press, pp 787-798

Gray JA, Moran PM, Grigoryan G, Peters SL, Young AMJ, Joseph MH (1997): Latent inhibition: the nucleus accumbens connection revisited. Behav Brain Res 88:27-34

Gray NS, Hemsley DR, Gray JA (1992): Abolition of latent inhibition in acute, but not chronic, schizophrenics. Neurol Psychiatry Brain Res 1:83-89

Gray NS, Pilowsky LS, Gray JA, Kerwin RW (1995): Latent inhibition in drug naive schizophrenics: relationship to duration of illness and dopamine $\mathrm{D}_{2}$ binding using SPET. Schizophr Res 17:95-107

Hellman PA, Crider A, Solomon PR (1983): Interaction of tail pressure stress and d-amphetamine in disruption of the rat's ability to ignore an irrelevant stimulus. Behav Neurosci 97:1017-1021

Hitchcock JM, Lister S, Fischer TR, Wettstein JG (1997): Disruption of latent inhibition in the rat by the 5-HT2 agonist DOI: effects of MDL 100,907, clozapine, risperidone and haloperidol. Behav Brain Res 88:43-49

Kalivas PW, Stewart J (1991): Dopamine transmission in the initiation and expression of drug- and stress-induced sensitization of motor activity. Brain Res Rev 16:223-244

Killcross AS, Robbins TW (1993): Differential effects of intraaccumbens and systemic amphetamine on latent inhibition using an on-baseline, within-subject conditioned suppression paradigm. Psychopharmacology 110: 479-489

Kokkinidis L, Anisman H (1980): Amphetamine models of paranoid schizophrenia: an overview and elaboration of animal experimentation. Psychol Bull 88:551-579

Kokkinidis L, Zacharko RM, Predy PA (1980): Post-amphetamine depression of self-stimulation responding from the substantia nigra: reversal by tricyclic antidepressants. Pharmacol Biochem Behav 13:379-383

Kokkinidis L, Zacharko RM, Anisman H (1986): Amphetamine withdrawal: a behavioral evaluation. Life Sci $38: 1617-1623$

Kuroki T, Meltzer HY, Ichikawa J (1999): Effects of antipsychotic drugs on extracellular dopamine levels in rat medial prefrontal cortex and nucleus accumbens. J Pharmacol Exp Ther 288:774-781 
Laruelle M (2000): The role of endogenous sensitization in the pathophysiology of schizophrenia: implications from recent brain imaging studies. Brain Res Rev 31:371-384

Leith NJ, Barrett RJ (1976): Amphetamine and the reward system: evidence for tolerance and post-drug depression. Psychopharmacology (Berl) 46:19-25

Levy AD, Kim JJ, Ellison GD (1988): Chronic amphetamine alters D-2 but not D-1 agonist-induced behavioral responses in rats. Life Sci 43:1207-1213

Liebermann JA, Kinon BJ, Loebel AD (1990): Dopaminergic mechanisms in ideopathic and drug-induced psychoses. Schizophr Bull 16:97-109

Lin D, Koob GF, Markou A (1999): Differential effects of withdrawal from chronic amphetamine or fluoxetine administration on brain stimulation reward in the rat interactions between the two drugs. Psychopharmacology (Berl) 145:283-294

Lubow RE (1973): Latent inhibition. Psychol Bull 79:398-407

Meltzer HT (1989): Clinical studies on the mechanism of action of clozapine: the dopamine-serotonin hypothesis of schizophrenia. Psychopharmacology (Berl) 99(Suppl):18-27

Moran PM, Fischer JM, Hitchcock JM, Moser PC (1996): Effects of clozapine on latent inhibition in the rat. Behav Pharmacol 7:42-48

Moser PC, Hitchcock JM, Lister S, Moran PM (2000): The pharmacology of latent inhibition as an animal model of schizophrenia. Brain Res Rev 33:275-307

Moser PC, Moran PM, Frank RA, Kehne JH (1996): Reversal of amphetamine-induced behaviours by MDL 100,907, a selective 5-HT2A antagonist. Behav Brain Res 73:163-167

Murphy CA, Pezze M-A, Feldon J, Heidbreder C (2000): Differential involvement of dopamine in the shell and the core of the nucleus accumbens in the expression of latent inhibition to an aversively-conditioned stimulus. Neuroscience 97:469-477

Murphy CA, Fend M, Russig H, Feldon J (2001): Latent inhibition but not prepulse inhibition is reduced during withdrawal from an escalating dosage schedule of amphetamine. Behav Neurosci 115:1247-1256

Niemegeers CJE, Verbruggen FJ, Janssen PAJ (1969): The influence of various neuroleptic drugs on shock avoidance responding in rats. Psychopharmacologia 16:161-174

Ogren SO, Archer T (1994): Effects of typical and atypical antipsychotic drugs on two-way active avoidance. Relationship to DA receptor blocking profile. Psychopharmacology (Berl) 114:383-391

Paulson PE, Camp DM, Robinson TE (1991): Time course of transient behavioral depression and persistent behavioral sensitization in relation to regional brain monoamine concentrations during amphetamine withdrawal in rats. Psychopharmacology (Berl) 103:480-492

Paulson PE, Robinson TE (1995): Amphetamine-induced time-dependent sensitization of dopamine neurotransmission in the dorsal and ventral striatum: a microdialysis study in behaving rats. Synapse 19:56-65

Peters SL, Joseph MH (1993): Haloperidol potentiation of latent inhibition in rats: Evidence for a critical role at conditioning rather than pre-exposure. Behav Pharmacol 4:183-186

Pezze M-A, Feldon J, Murphy CA (In press): Increased con- ditioned fear response and altered balance of dopamine in the shell and core of the nucleus accumbens during amphetamine withdrawal. Neuropharmacology

Robinson TE, Becker JB (1986): Enduring changes in brain and behavior produced by chronic amphetamine administration: a review and evaluation of animal models of amphetamine psychosis. Brain Res Rev 11:157-198

Rossetti ZL, Hmaidan Y, Gessa GL (1992): Marked inhibition of mesolimbic dopamine release: a common feature of ethanol, morphine, cocaine and amphetamine abstinence in rats. Eur J Pharmacol 221:227-234

Roth RH, Tam SY, Ida Y, Yang JX, Deutch AY (1988): Stress and the mesocorticolimbic dopamine systems. Ann N Y Acad Sci 573:138-147

Russig H, Murphy CA, Pezze MA, Feldon J (2001): Withdrawal from intermittent and escalating dosage schedules of amphetamine produces sensitisation, but is not associated with depressive symptoms in rats. Behav Pharmacol 12(Suppl 1):87

Schotte A, Janssen PFM, Gommeren W, Luyten WHML, Van Gompel P, Lesage AS, De Loore K, Leysen JE (1996): Risperidone compared with new and reference antipsychotic drugs: in vitro and in vivo receptor binding. Psychopharmacology (Berl) 124:57-73

Segal DS, Kuczenski R (1992): In vivo microdialysis reveals a diminished amphetamine- induced DA response corresponding to behavioral sensitization produced by repeated amphetamine pretreatment. Brain Res 571:330-337

Shadach E, Feldon J, Weiner I (1999): Clozapine-induced potentiation of latent inhibition is due to its action in the conditioning stage: implications for the mechanism of action of antipsychotic drugs. Int J Neuropsychopharmcol 2:283-291

Shadach E, Gaisler I, Schiller D, Weiner I (2000): The latent inhibition model dissociates between clozapine, haloperidol, and ritanserin. Neuropsychopharmacology 23:151-161

Snyder SH (1973): Amphetamine psychosis: a "model" schizophrenia mediated by catecholamines. Am J Psychiatry 130:61-67

Solomon PR, Crider A, Winkelman JW, Turi A, Kamer RM, Kaplan LJ (1981): Disrupted latent inhibition in the rat with chronic amphetamine or haloperidol-induced supersensitivity: relationship to schizophrenic attention disorder. Biol Psychiatry 16:519-537

Solomon PR, Staton DM (1982): Differential effect of microinjections of $\mathrm{d}$-amphetamine into the nucleus accumbens or the caudate-putamen on the rat's ability to ignore an irrevelant stimulus. Biol Psychiatry 17:742-756

Spohn HE, Lacoursiere RB, Thompson K, Coyne L (1977): Phenothiazine effects on psychological and psychopharmacological dysfunction in chronic schizophrenics. Arch Gen Psychiatry 34:633-644

Swerdlow NR, Braff DL, Hartston H, Perry W, Geyer MA (1996): Latent inhibition in schizophrenia. Schizophr Res 20:91-103

Vaitl D, Lipp V (1997): Latent inhibition and autonomic responses: A psycholophysiological approach. Behav Brain Res 88:85-94

Van Tol HHM, Bunzow JR, Guan HC, Sunuahara RK, Seeman P, Niznik HB, Civelli O (1991): Cloning of the gene 
for human dopamine $\mathrm{D}_{4}$ receptor with high affinity for the antipsychotic clozapine. Nature 350:610-614

Warburton EC, Joseph MH, Feldon J, Weiner I, Gray JA (1994): Antagonism of amphetamine-induced disruption of latent inhibition in rats by haloperidol and odansetron -implications for a possible antipsychotic action of odansetron. Psychopharmacology (Berl) 114:657-664

Weiner I, Lubow RE, Feldon J (1984): Abolition of the expression but not the acquisition of latent inhibition by chronic amphetamine in rats. Psychopharmacology (Berl) 83:194-199

Weiner I, Feldon J (1987): Facilitation of latent inhibition by haloperidol. Psychopharmacology (Berl) 91:248-253

Weiner I, Feldon J, Katz Y (1987): Facilitation of the expression but not the acquisition of latent inhibition by haloperidol in rats. Pharmacol Biochem Behav 26:241-246

Weiner I, Lubow RE, Feldon J (1988): Disruption of latent inhibition by acute administration of low doses of amphetamine. Pharmacol Biochem Behav 30:871-878

Weiner I (1990): Neural substrates of latent inhibition: the switching model. Psychol Bull 108:442-461

Weiner I, Gal G, Rawlins JN, Feldon J (1996a): Differential involvement of the shell and core subterritories of the nucleus accumbens in latent inhibition and amphetamine-induced activity. Behav Brain Res 81:123-133

Weiner I, Schadach E, Tarrasch R, Kidron R, Feldon J (1996b): The latent inhibition model of schizophrenia: Further validation using the atypical neuroleptic clozapine. Biol Psychiatry 40:834-843

Weiner I, Feldon J (1997): The switching model of latent inhibition: an update of neural substrates. Behav Brain Res 88:11-25

Weiner I, Schadach E, Barkai R, Feldon J (1997): Haloperidol and clozapine induced enhancement of latent inhibition with extended conditioning: Implications for the mech- anism of action of neuroleptic drugs. Neuropsychopharmacology 16:42-50

Weiss F, Imperato A, Casu MA, Mascia MS, Gessa GL (1997): Opposite effects of stress on dopamine release in the limbic system of drug naive and chronically amphetamine-treated rats. Eur J Pharmacol 337:219-222

Williams JH, Wellmann NA, Geaney DP, Cowen PJ, Feldon J, Rawlins JN (1996): Antipsychotic drug effects in a model of schizophrenic attentional disorder: a randomized controlled trial of the effects of haloperidol on latent inhibition in healthy people. Biol Psychiatry 40:1135-1143

Williams JH, Wellmann NA, Geaney DP, Feldon J, Cowen PJ, Rawlins JN (1997): Haloperidol enhances latent inhibition in visual tasks in healthy people. Psychopharmacology (Berl) 133:262-268

Williams JH, Wellmann NA, Geaney DP, Cowen PJ, Feldon J, Rawlins JN (1998): Reduced latent inhibition in people with schizophrenia: An effect of psychosis or of its treatment. Br J Psychiatry 172:243-249

Wolf ME, White FJ, Nassar R, Brooderson RJ, Khansa MR (1993): Differential development of autoreceptor subsensitivity and enhanced dopamine release during amphetamine sensitization. J Pharmacol Exp Ther 264:249-255

Young AMJ, Joseph MH, Gray JA (1993): Latent inhibition of conditioned dopamine release in rat nucleus accumbens. Neuroscience 54:5-9

Zhang K, Tarazi FI, Baldessarini RJ (2000a): Dopamine $\mathrm{D}_{4}$ receptors in rat forebrain: unchanged with amphetamine-induced behavioral sensitization. Neuroscience 97:211-213

Zhang K, Tarazi FI, Campbell A, Baldessarini RJ (2000b): $\mathrm{GABA}_{\mathrm{B}}$ receptors: altered coupling to G-proteins in rats sensitized to amphetamine. Neuroscience 101:5-10 